\title{
Treatment of patients with comorbid depression and diabetes with metformin and milnacipran
}

\author{
This article was published in the following Dove Press journal: \\ Neuropsychiatric Disease and Treatment \\ 24 August 2010 \\ Number of times this article has been viewed
}

\section{Peter Hofmann \\ University Clinic of Psychiatry, Graz Medical University, Graz, Austria}

\begin{abstract}
Depression is twice as frequent in patients with diabetes as in the general population, and has a negative impact on self-care, adherence to treatment, and the general prognosis of diabetes. This underscores the importance of screening all diabetic patients for depression and, if necessary, treating it with an effective antidepressant drug in parallel with standard diabetes treatment. In a recent study, a simple two-question screening tool was used to screen diabetic patients for comorbid depression. The effects of the serotonin and norepinephrine reuptake inhibitor antidepressant, milnacipran, on metabolic parameters and depressive symptoms in 64 diabetic patients with comorbid depression detected by this screen were studied. Patients received milnacipran for 6 months, in addition to standard diabetes treatment with metformin. At the end of the study, $72 \%$ of patients had responded to antidepressant treatment $(\geq 50 \%$ reduction of baseline Beck Depression Score). The proportion of patients with $<8 \%$ glycosylated hemoglobin $\mathrm{HbA}_{1 \mathrm{c}}$ (a common indication in diabetes of the need for intensive therapeutic intervention) had decreased significantly from $46.6 \%$ at baseline to $6.9 \%$. $\mathrm{HbA}_{1 \mathrm{c}}$, fasting blood glucose, body mass index, total and low-density lipoprotein cholesterol, and serum triglyceride levels were all significantly decreased in patients with an antidepressant response, but not in patients whose depressive symptoms had not responded to milnacipran.
\end{abstract}

Keywords: depression, diabetes, milnacipran, serotonin, norepinephrine, reuptake inhibitors

\section{Introduction}

Depression is common in patients with diabetes mellitus. ${ }^{1}$ The prevalence of depression (major and minor) in patients with type 2 diabetes is reported to be almost twice that of the general population, ie, $17.6 \%$ versus $9.8 \%$, respectively. ${ }^{2}$ The relationship between comorbid depression and diabetes is complex (Figure 1) and the pathophysiology is still unclear. As with other severe chronic illnesses, psychologic factors associated with suffering and diminished quality of life related to diabetes may trigger or enhance depressive symptoms. ${ }^{3}$ There is evidence, however, to suggest that depression may, in many cases, precede diabetes and act as a causal factor for weight gain and subsequent development of diabetes. ${ }^{4}$ Approximately $80 \%$ of diabetic patients are overweight or obese, and a complex relationship exists between obesity and depression. ${ }^{5-7}$ Depression can be a precursor or aggravating factor in the development of obesity, but there is also evidence that obesity may lead to depression. ${ }^{8,9}$ The comorbidity of diabetes and depression is associated with a significantly increased risk of death from all causes, beyond risks inherent with diabetes or depression alone. ${ }^{10-12}$ There appears to be a clear synergistic interaction between diabetes and depression, resulting in decreased metabolic control, a higher incidence of vascular complications, and decreased quality of life in 


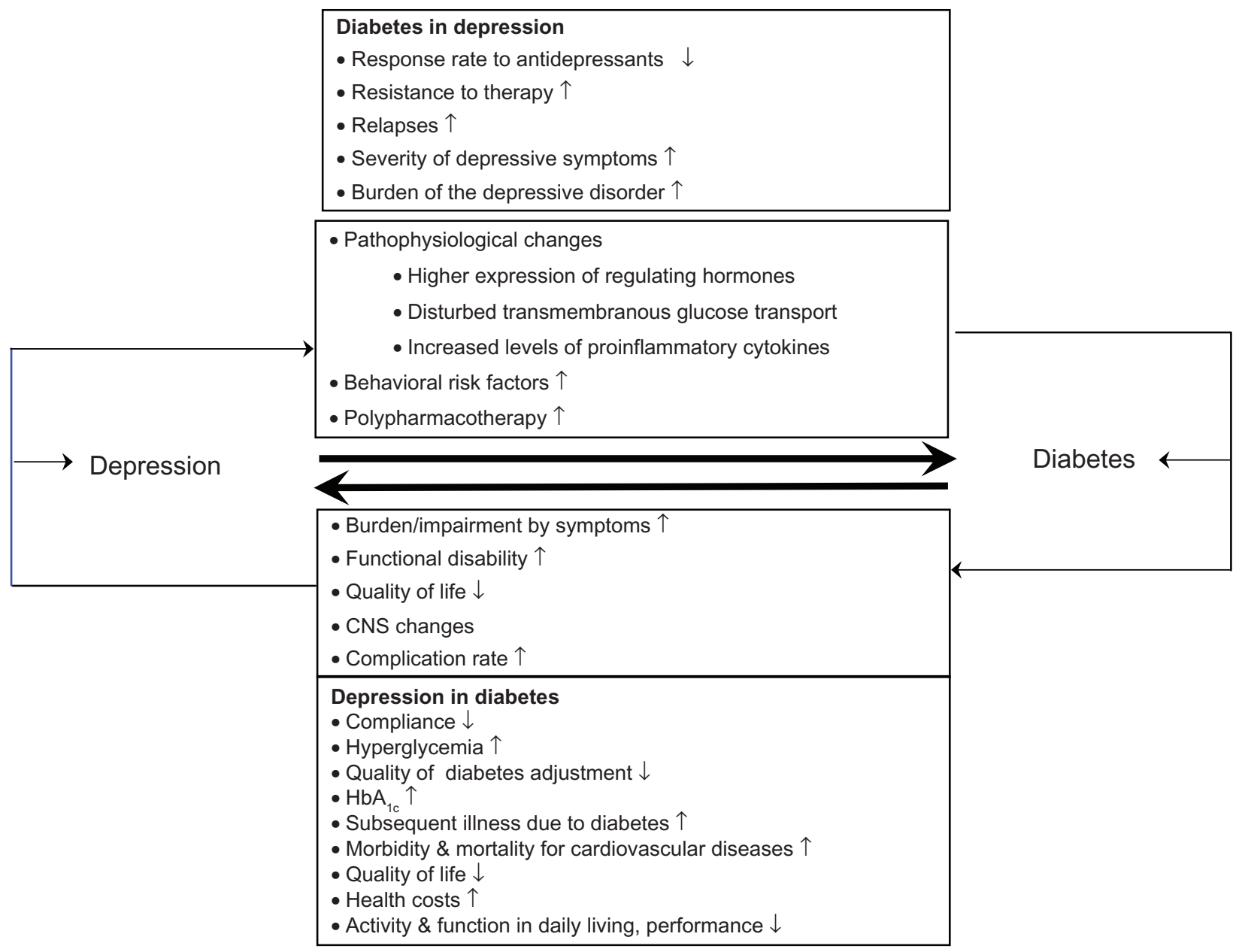

Figure I Complex interactions between depression and diabetes. Modified from Regen et al..$^{34}$

comorbid sufferers. ${ }^{1,10,13,14}$ Despite the importance of comorbid depression on the prognosis of diabetes, diabetic patients are rarely screened for depressive symptoms, and depression frequently goes undetected and therefore untreated.

\section{Treatment of comorbid depression in diabetic patients}

If the presence of depression aggravates or precipitates diabetes, what are the effects on diabetic symptoms of treating the depression with antidepressant medication? The impact of antidepressant therapy on metabolic and anthropometric parameters in diabetic patients with comorbid depression is still poorly understood. ${ }^{15-17}$

Studies with antidepressants have shown variable effects on metabolic control. In a study with sertraline, glycosylated hemoglobin $\left(\mathrm{HbA}_{1 \mathrm{c}}\right)$ levels were reduced during treatment, but did not differ between the sertraline and placebo groups, ${ }^{15,16}$ whereas no significant reduction in $\mathrm{HbA}_{1 \mathrm{c}}$ levels was observed in patients treated with fluoxetine or paroxetine, although their depressive symptoms were significantly improved. ${ }^{17}$ Similarly, although escitalopram resulted in a significant reduction of depression score, there was only a small and nonsignificant reduction in fasting blood glucose (FBG) levels and $\mathrm{HbA}_{1 \mathrm{c}}$ levels. ${ }^{18}$ It would thus appear that selective serotonin reuptake inhibitors (SSRIs) do not have any major effect on metabolic control, even when they produce a significant effect on depressive symptoms.

The expression of norepinephrine transporter mRNA has been shown to be decreased in the locus coeruleus and other brain regions in experimentally diabetic rats, ${ }^{19}$ suggesting a possible role for this neurotransmitter in the development of diabetes, especially in the case of comorbid depression where this monoamine is thought to be reduced.

A recent study ${ }^{20}$ has evaluated the effect of long-term treatment with the antidepressant, milnacipran, on depressive symptoms and metabolic parameters in type 2 diabetic patients with comorbid depression. Milnacipran is a serotonin and norepinephrine reuptake inhibitor (SNRI) ${ }^{21}$ which inhibits 
the reuptake of the two monoamines with the most balanced potency ratio of all the SNRIs (1:1.6 for milnacipran; 1:10 for duloxetine, and 1:30 for venlafaxine). ${ }^{22}$ Some studies have even shown that milnacipran inhibits norepinephrine uptake with greater potency than serotonin $(2.22: 1) .{ }^{23}$ It is thus the most noradrenergic of the SNRI antidepressants. In addition to being effective and well tolerated, ${ }^{21}$ milnacipran has a characteristic which makes it particularly attractive for treating diabetic patients with comorbid depression. It is one of the rare antidepressants that has no interaction with the cytochrome $\mathrm{P} 450$ enzyme system, ${ }^{24}$ and thus possesses a very low risk of drug-drug interactions. Because diabetic patients, especially those with comorbid depression, are likely to be treated with multiple medications, the risk of drug-drug interactions should be of constant concern.

This open-label longitudinal study ${ }^{20}$ was conducted in outpatients who fulfilled the criteria for type 2 diabetes mellitus as defined by the American Diabetes Association, ${ }^{25}$ and who had been screened positively for comorbid depression. Because diabetologists are not psychiatrists, it was necessary to find a simple way of screening diabetic patients for depressive symptoms. A simple two-question screen, based on the questionnaire developed by Whooley et $\mathrm{al}^{26}$ was used:

Question 1. During the past month, have you often been bothered by feeling down, depressed, or hopeless?

Question 2. During the past month, have you often been bothered by little interest or pleasure in doing things?

A positive answer to both questions indicated the probable presence of depressive symptoms. A diagnosis of depression was subsequently confirmed according to ICD-10 criteria for a depressive episode using the 12-item Major Depression Inventory (MDI) questionnaire. ${ }^{27}$

$\mathrm{FBG}, \mathrm{HbA}_{1 \mathrm{c}}$, total cholesterol, LDL-cholesterol, high-density lipoprotein (HDL)-cholesterol, serum triglycerides, and weight were measured at baseline and after 6 months of treatment. Height was measured at baseline and was assumed to remain constant throughout the study. The severity of depression was measured at baseline and after 1, 3, and 6 months of treatment using the Beck Depression Inventory (BDI). ${ }^{28}$

All patients received standard diabetes treatment, ie, metformin (500-2000 $\mathrm{mg} /$ day) as recommended by the Guidelines of the Austrian Diabetes Association. ${ }^{29}$ Milnacipran treatment was initiated at $25-50 \mathrm{mg} /$ day, increasing to $100 \mathrm{mg} /$ day ( $50 \mathrm{mg}$ twice daily) after a few days. Clinicians chose the initial dose and subsequent dose adjustments on the basis of the patient's clinical response and tolerance of the drug.
Patients were generally obese, with a mean body mass index (BMI) of $<30$ and with moderate to poor glycemic control (see Table 1). Of the 58 patients who completed the trial, $47 \%$ had a baseline $\mathrm{HbA}_{1 \mathrm{c}}<8 \%$, usually considered as an indicator of the need for intensive therapeutic intervention. The mean BDI score at baseline was 23.2, indicating a moderate to severe level of depression. Most of the patients $(81 \%)$ had never taken antidiabetic drugs, their condition being managed by lifestyle adjustment only, and the majority $(90 \%)$ had never taken antidepressant medication.

BDI scores improved progressively during the study (Figure 2). After 6 months, nearly $72 \%$ of patients had responded to treatment (defined as a $\geq 50 \%$ decrease in baseline BDI score). There was no difference between responders and nonresponders for age, severity of depression, metabolic control, or BMI at baseline.

Over the 6 months of the study, FBG levels, $\mathrm{HbA}_{1 \mathrm{c}}$, body weight, BMI, total cholesterol, LDL-cholesterol, and serum triglycerides were all significantly improved (Figure 3 ) and the proportion of patients with $\mathrm{HbA}_{1 \mathrm{c}}<8 \%$ decreased significantly from $47 \%$ to $7 \%$. Interestingly, this improvement in diabetic symptoms was principally due to reductions in patients with a response in their depressive symptoms. As shown in Figure 4, depression-responsive patients had significant improvements in all of the metabolic and anthropometric parameters studied, while nonresponders showed no significant improvements. Interestingly, there was a significant weight loss during treatment of these overweight or obese patients (Figure 5).

The contrast with the results of similar studies carried out with SSRIs is consistent with the importance of the role of noradrenergic neurotransmission which would

Table I Metabolic parameters at baseline and after 6 months of treatment with milnacipran for all patients completing the study

\begin{tabular}{llll}
\hline Parameter & Baseline & Six months & $\boldsymbol{P}$ \\
\hline FBG $(\mathrm{mg} / \mathrm{dL})$ & 155.0 & 113.0 & $<0.0001$ \\
HbA $_{\text {Ic }}(\%$ of total Hb) & 7.9 & 6.9 & $<0.000$ I \\
Bodyweight $(\mathrm{kg})$ & 90.5 & 84 & $<0.001$ \\
BMI $\left(\mathrm{kg} / \mathrm{m}^{2}\right)$ & 30.4 & 28 & $<0.001$ \\
Total chol $(\mathrm{mg} / \mathrm{dL})$ & 199.5 & 178 & $<0.000$ I \\
LDL-chol $(\mathrm{mg} / \mathrm{dL})$ & 117 & 108 & $<0.001$ \\
HDL-chol $(\mathrm{mg} / \mathrm{dL})$ & 47.0 & 48.0 & $\mathrm{NS}$ \\
Triglyc $(\mathrm{mg} / \mathrm{dL})$ & 190 & 157 & $<0.001$ \\
\hline
\end{tabular}

Note: All values are given as the median. $P=$ significance of the difference between baseline and six-month values (paired t-test).

Abbreviations: $\mathrm{HbA}_{\mathrm{lc}}$, glycosylated hemoglobin; $\mathrm{FBG}$, fasting blood glucose; BMI, body mass index; total chol, total cholesterol; LDL-chol, low-density lipoprotein cholesterol; HDL chol, high-density lipoprotein cholesterol; Triglyc, serum triglycerides; NS, not significant. 


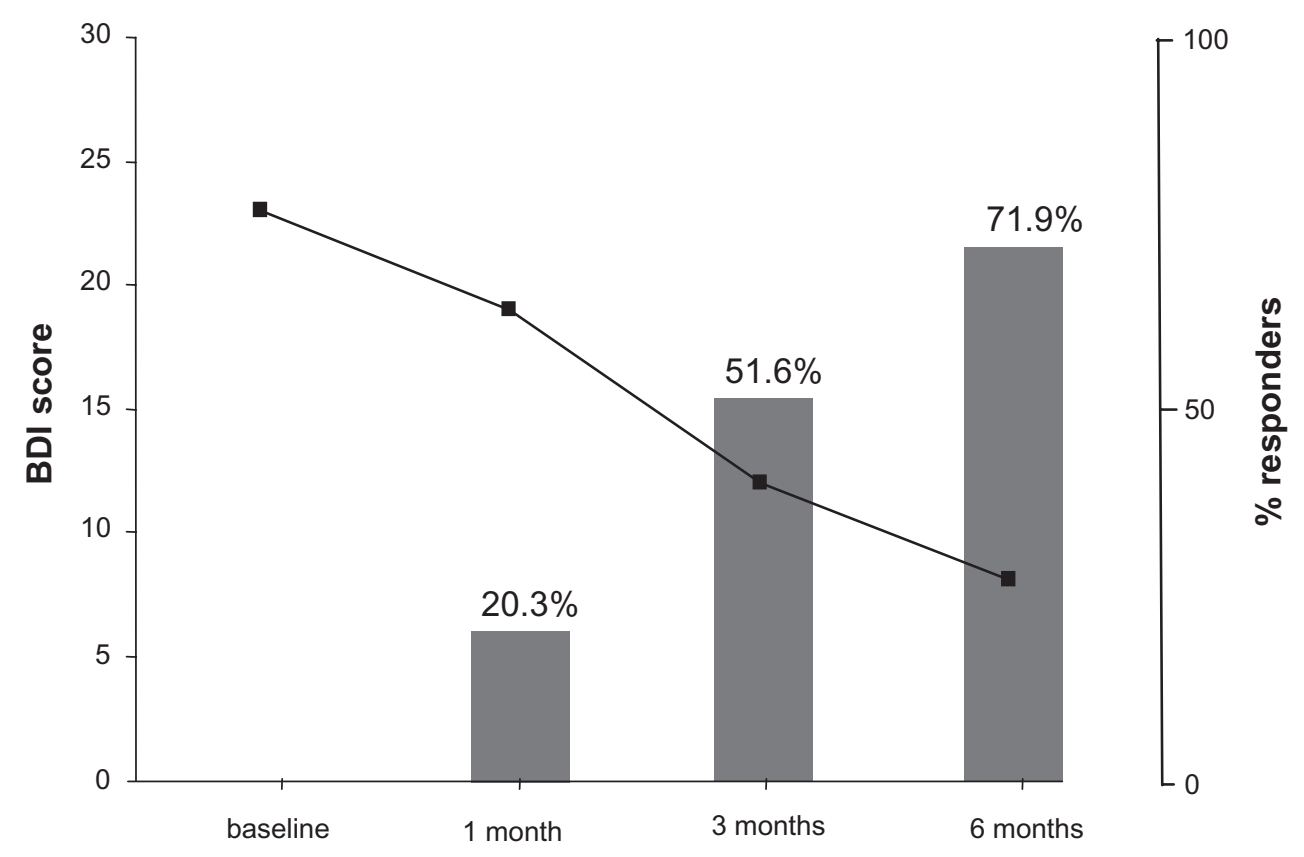

Figure 2 Evolution of depression rating throughout the study.

Note: The squares and single line refer to the depression rating as measured by the BDI (left hand axis). The gray columns refer to the percentage of patients responding to treatment ( $\geq 50 \%$ decrease in baseline Beck Depression Inventory score). Values are medians for all 64 patients who started the study.

be stimulated by the inhibition of the norepinephrine transporter by milnacipran. Indeed, another study of a compound with a marked noradrenergic component, bupropion, found that BMI and $\mathrm{HbA}_{1 \mathrm{c}}$ levels decreased significantly during the acute treatment phase with an association between reduction of depression severity and reduction of $\mathrm{HbA}_{1 \mathrm{c}}$ levels. ${ }^{30}$ Clearly, further studies are required to investigate the possible importance of the noradrenergic component of antidepressant action on metabolic parameters in diabetes.

\section{Discussion}

Despite the negative impact of untreated depression on diabetes care and prognosis, ${ }^{31,32}$ depression is still underrecognized in diabetic patients. Diabetes is one of the most psychologically and behaviorally demanding of the

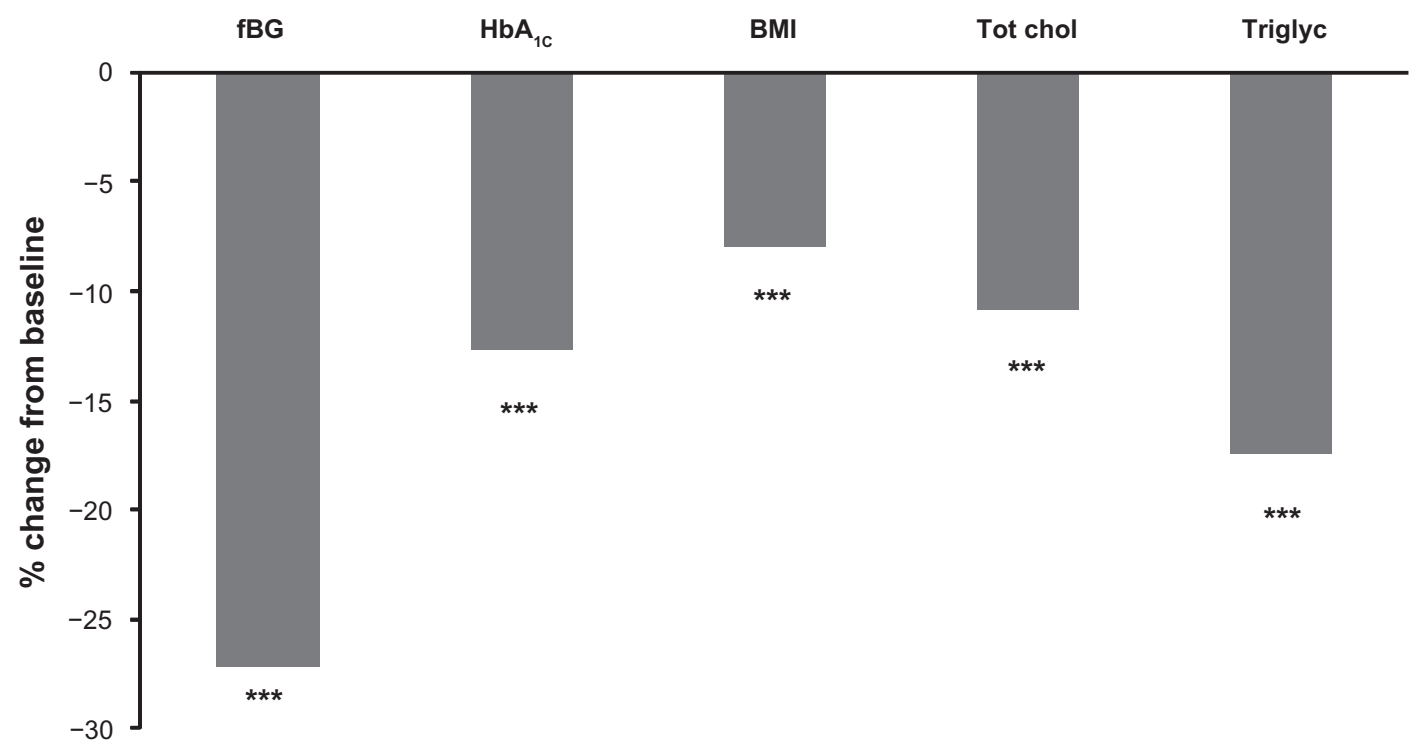

Figure 3 Change in metabolic parameters during 6 months of milnacipran treatment.

$* * * P<0.001$ compared with baseline values. Values are medians for all 58 patients who completed the study.

Abbreviations: $\mathrm{FBG}$, fasting blood glucose; $\mathrm{HbA}_{\mathrm{Ic}}$, glycosylated hemoglobin; total chol, total cholesterol; triglyc, serum triglycerides. 


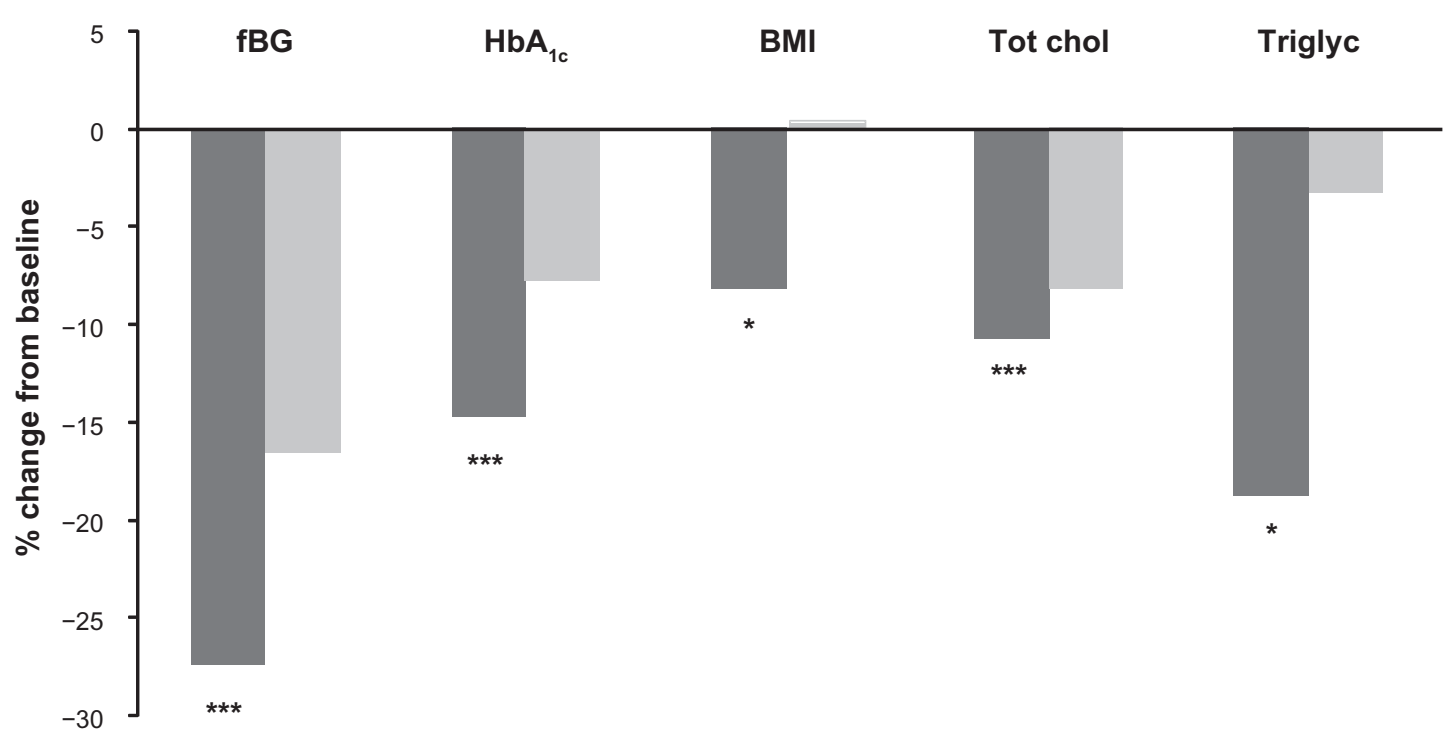

Figure 4 Change in metabolic parameters in antidepressant responders and nonresponders during 6 months of milnacipran treatment.

Note: Dark gray columns = antidepressant responders ( $\geq 50 \%$ decrease in baseline BDI score, $n=46$ ); light gray columns = antidepressant nonresponders, $n=12$ ). Values are medians.

$* P<0.05 ; * * * P<0.00$ I compared with baseline values.

Abbreviations: $\mathrm{FBG}$, fasting blood glucose; $\mathrm{HbA}_{l c}$, glycosylated hemoglobin; total chol, total cholesterol; triglyc, serum triglycerides.

chronic medical illnesses. At least $90 \%$ of diabetes management is conducted by the patient himself or herself. The effect of comorbid depression on the patient's motivation for self-care can result in unfavorable or even potentially fatal development of the disease. ${ }^{33}$ Although many physicians are aware of the importance of detecting comorbid depression in diabetic patients, many of them find it difficult to deal with in practice. Most diagnostic tools for screening depression are complicated, time-consuming, or require at least some psychiatric training. The simple two-question screen used

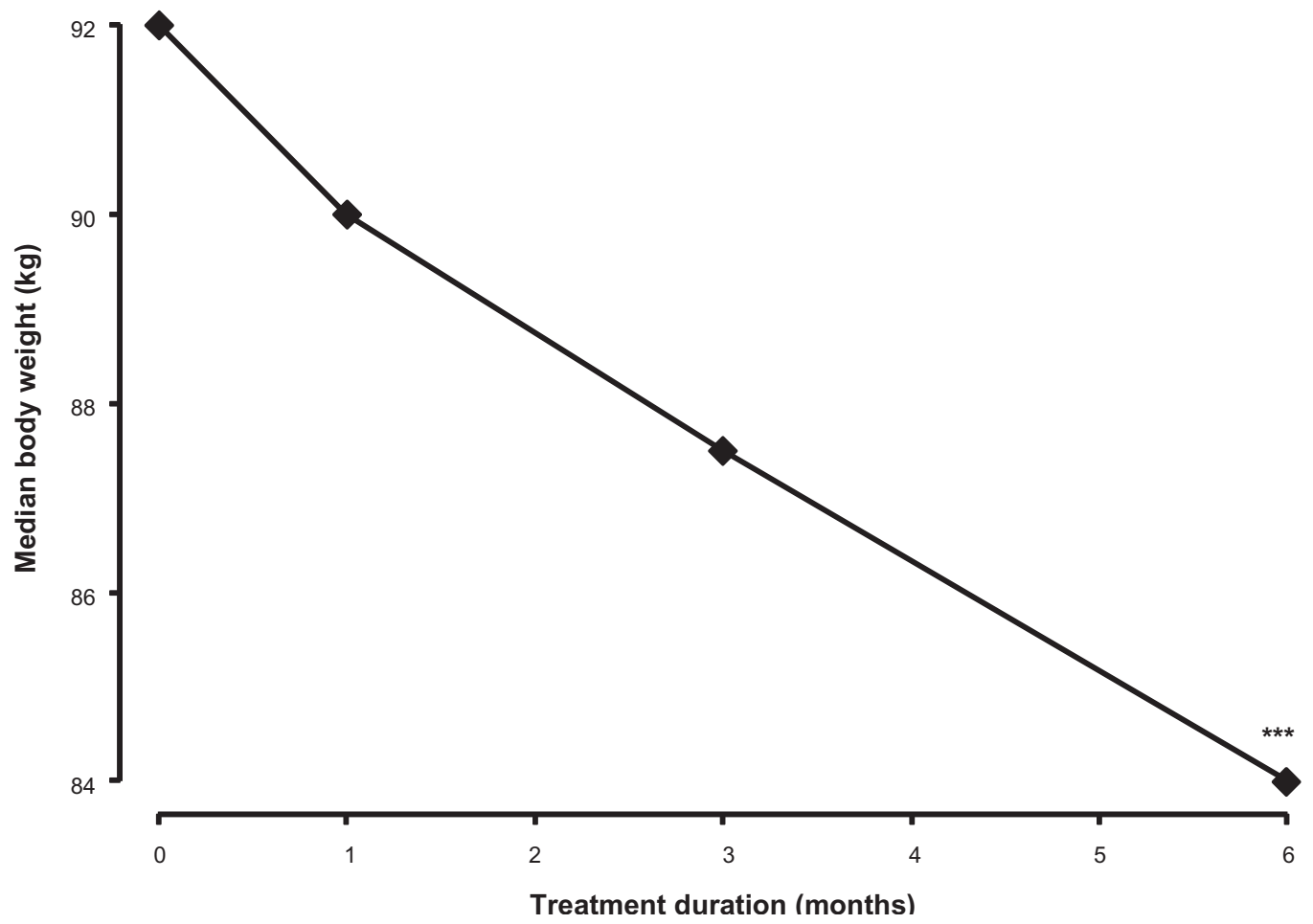

Figure 5 Change of body weight in antidepressant responders during 6 months of milnacipran treatment.

Values are medians for all 46 patients who responded to the antidepressant and completed the study ( $\geq 50 \%$ decrease in baseline Beck Depression Inventory score). $* * * P<0.001$ compared with baseline values. 
in the above study was based on the two principal criteria of a depressive episode, ie, a period of at least 2 weeks during which there is either depressed mood and/or the loss of interest or pleasure in nearly all activities. A "no" response to both of the two questions means that depression is highly unlikely. For the rare patients who answer "yes" to only one of the questions, other symptoms should be elicited to confirm or refute a diagnosis of depression. Patients who reply positively to both questions are invariably depressed, and in the above study there were no "false positives", ie, patients identified as possibly depressive who were subsequently found not to have a diagnosis of depression.

Once comorbid depression has been diagnosed in a diabetic patient it needs to be aggressively treated with an effective antidepressant. Although the demonstration is not yet definitive, the available evidence suggests that an antidepressant with a noradrenergic component is more likely to have a favorable impact on both diabetic and depressive symptoms. ${ }^{15-18}$ While SSRIs appear to be effective in treating depressive symptoms they seem to have little influence on diabetic symptoms in contrast with the SNRI, milnacipran, ${ }^{20}$ and the catecholaminergic antidepressant, bupropion. ${ }^{29}$

As with all polymedicated patients, the physician needs to be particularly vigilant and wary of potential drug-drug interactions. The use of an antidepressant such as milnacipran, which has no interaction with any cytochrome P450 enzyme, ${ }^{24}$ reduces the risk of interactions.

Increasingly in modern medicine patient health is being seen as an integrated whole rather than as a collection of more or less independent complaints. The interaction between depression and diabetes, while still poorly understood, is extremely clear. Studies like the one illustrated here show that successful therapy of depression can have far reaching consequences for prognosis of diabetes and thus provide important global benefit for the patient.

\section{Disclosure}

The author is a consultant for Germania Pharmaceutika, who sell milnacipran in Austria.

\section{References}

1. Katon WJ. The co-morbidity of diabetes mellitus and depression. Am J Med. 2008;121(11 Suppl 2):S8-S15.

2. Ali S, Stone MA, Peters JL, Davies MJ, Khunti K. The prevalence of co-morbid depression in adults with Type 2 diabetes: A systematic review and meta-analysis. Diabet Med. 2006;23(11):1165-1173.

3. Talbot F, Nouwen A. A review of the relationship between depression and diabetes in adults: Is there a link? Diabetes Care. 2000;23(10):1556-1562.

4. Knol MJ, Twisk JW, Beekman AT, Heine RJ, Snoek FJ, Pouwer F. Depression as a risk factor for the onset of Type 2 diabetes mellitus. A meta-analysis. Diabetologia. 2006;49(5):837-845.
5. Dong C, Sanchez LE, Price RA. Relationship of obesity to depression: A family-based study. Int J Obes Relat Metab Disord. 2004;28(6):790-795.

6. Murphy JM, Horton NJ, Burke JD, et al. Obesity and weight gain in relation to depression: Findings from the Stirling County Study. Int J Obes (Lond). 2009;33(3):335-341.

7. Papakostas GI, Petersen T, Iosifescu DV, et al. Obesity among outpatients with major depressive disorder. Int $J$ Neuropsychopharmacol. 2005;8(1):59-63.

8. Russell-Jones D, Khan R. Insulin-associated weight gain in diabetes causes, effects and coping strategies. Diabetes Obes Metab. 2007;9(6): 799-812.

9. Onyike CU, Crum RM, Lee HB, Lyketsos CG, Eaton WW. Is obesity associated with major depression? Results from the Third National Health and Nutrition Examination Survey. Am J Epidemiol. 2003;158(12):1139-1147.

10. Egede LE, Nietert PJ, Zheng D. Depression and all-cause and coronary heart disease mortality among adults with and without diabetes. Diabetes Care. 2005;28(6):1339-1345.

11. Katon WJ, Russo JE, Von Korff M, Lin EH, Ludman E, Ciechanowski PS. Long-term effects on medical costs of improving depression outcomes in patients with depression and diabetes. Diabetes Care. 2008;31(6): 1155-1159.

12. Rush WA, Whitebird RR, Rush MR, Solberg LI, O’Connor PJ. Depression in patients with diabetes: Does it impact clinical goals? JAm Board Fam Med. 2008;21(5):392-397.

13. Egede LE, Ellis C. The effects of depression on diabetes knowledge, diabetes self-management, and perceived control in indigent patients with type 2 diabetes. Diabetes Technol Ther. 2008;10:213-219.

14. de Groot M, Anderson R, Freedland KE, Clouse RE, Lustman PJ. Association of depression and diabetes complications: A meta-analysis. Psychosom Med. 2001;63(4):619-630.

15. Lustman PJ, Freedland KE, Griffith LS, Clouse RE. Fluoxetine for depression in diabetes: A randomized double-blind placebo-controlled trial. Diabetes Care. 2000;23(5):618-623.

16. Lustman PJ, Clouse RE, Nix BD, et al. Sertraline for prevention of depression recurrence in diabetes mellitus: A randomized, double-blind, placebo-controlled trial. Arch Gen Psychiatry. 2006;63(5):521-529.

17. Gülseren L, Gülseren S, Hekimsoy Z, Mete L. Comparison of fluoxetine and paroxetine in Type II diabetes mellitus patients. Arch Med Res. 2005;36(2):159-165.

18. Amsterdam JD, Shults J, Rutherford N, Schwartz S. Safety and efficacy of s-citalopram in patients with co-morbid major depression and diabetes mellitus. Neuropsychobiology. 2006;54(4):208-214.

19. Petrisić MS, Augood SJ, Bicknell RJ. Monoamine transporter gene expression in the central nervous system in diabetes mellitus. J Neurochem. 1997;68(6):2435-2441.

20. Abrahamian H, Hofmann P, Prager R, Toplak H. Diabetes mellitus and co-morbid depression: Treatment with milnacipran results in significant improvement of both diseases (results from the Austrian MDDM study group). Neuropsychiatr Dis Treat. 2009;5:261-266.

21. Stahl SM, Grady MM, Moret C, Briley M. SNRIs: Their pharmacology, clinical efficacy, and tolerability in comparison with other classes of antidepressants. CNS Spectr. 2005;10(9):732-747.

22. Koch S, Hemrick-Luecke SK, Thompson LK, et al. Comparison of effects of dual transporter inhibitors on monoamine transporters and extracellular levels in rats. Neuropharmacology. 2003;45(7):935-944.

23. Vaishnavi SN, Nemeroff CB, Plott SJ, et al. Milnacipran: A comparative analysis of human monoamine uptake and transporter binding affinity. Biol Psychiatry. 2004;55(3):320-322.

24. Paris BL, Ogilvie BW, Scheinkoenig JA, Ndikum-Moffor F, Gibson R, Parkinson A. In vitro inhibition and induction of human liver cytochrome $\mathrm{p} 450$ enzymes by milnacipran. Drug Metab Dispos. 2009;37(10):2045-2054.

25. American Diabetes Association. Diagnosis and classification of diabetes mellitus. Diabetes Care. 2006;29 Suppl 1:S43-S48.

26. Whooley MA, Avins AL, Miranda J, Browner WS. Case-finding instruments for depression. Two questions are as good as many. J Gen Intern Med. 1997;12(7):439-445. 
27. Beck AT, Beamesderfer A. Assessment of depression: The depression inventory. Mod Probl Pharmacopsychiatry. 1974;7(0):151-169.

28. Bech P, Rasmussen NA, Olsen LR, Noerholm V, Abildgaard W. The sensitivity and specificity of the Major Depression Inventory, using the Present State Examination as the index of diagnostic validity. $J$ Affect Disord. 2001;66(2-3):159-164.

29. Austrian Diabetes Association. Therapeutic guidelines of the Austrian Diabetes Association. Available from: http://www.oedg.org/pdf/ Leitlinien_2007.pdf Accessed on May 24, 2010.

30. Lustman PJ, Williams MM, Sayuk GS, Nix BD, Clouse RE. Factors influencing glycemic control in Type 2 diabetes during acute- and maintenance-phase treatment of major depressive disorder with bupropion Diabetes Care. 2007;30(3):459-466.
31. Ciechanowski PS, Katon WJ, Russo JE. Depression and diabetes: impact of depressive symptoms on adherence, function, and costs. Arch Intern Med. 2000;160(21):3278-3285.

32. Paile-Hyvärinen M, Wahlbeck K, Eriksson JG. Quality of life and metabolic status in mildly depressed women with Type 2 diabetes treated with paroxetine: A single-blind randomised placebo controlled trial. BMC Fam Pract. 2003;4:7.

33. Gonzalez JS, Peyrot M, McCarl LA, et al. Depression and wdiabetes treatment nonadherence: A meta-analysis. Diabetes Care. 2008;31(12): 2398-2403.

34. Regen F, Merkl A, Heuser I, Dettling M, Anghelescu I. Diabetes and depression. Dtsch Med Wochenschr. 2005;130(17):1097-1102.

\section{Publish your work in this journal}

Neuropsychiatric Disease and Treatment is an international, peerreviewed journal of clinical therapeutics and pharmacology focusing on concise rapid reporting of clinical or pre-clinical studies on a range of neuropsychiatric and neurological disorders. This journal is indexed on PubMed Central, the 'PsycINFO' database and CAS, and is the official

Submit your manuscript here: http://www.dovepress.com/neuropsychiatric-disease-and-treatment-journal journal of The International Neuropsychiatric Association (INA). The manuscript management system is completely online and includes a very quick and fair peer-review system, which is all easy to use. Visit http://www.dovepress.com/testimonials.php to read real quotes from published authors. 